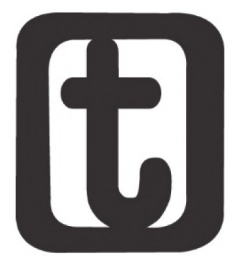

\title{
CRIANÇAS E ADOLESCENTES: O SISTEMA DE PROTEÇÃO SOCIAL EM PERNAMBUCO
}

Children and adolescents: the social protection system in Pernambuco

\section{Elisa Celina Alcantara Carvalho Mélo* Nathália Gregório de Santana**}

\section{RESUMO}

O presente artigo tem como objetivo central analisar os tipos de violações de direitos atendidas nos CRAS e CREAS do Estado de Pernambuco, no que diz respeito a crianças e adolescentes. Para tal reflexão, foi necessária uma revisão bibliográfica sobre as categorias: questão social, Estado, direitos e política social, além da reinteração das normativas, legislações e políticas vigentes no Brasil, em particular em Pernambuco sobre os usuários supracitados. Ainda nesse ensejo, os dados foram extraídos das planilhas anuais sobre os relatórios mensais de atendimentos dos CRAS e CREAS de 2016 no site do Ministério de Desenvolvimento Social e Combate à Fome (MDS) . Vale destacar, que mesmo diante dos avanços trazidos por meio da Constituição Federal de 1988 e do Estatuto da Criança e do Adolescente em 1990, as violações de direitos cometidas contra crianças e adolescentes ainda são alarmantes.

\section{PALAVRAS-CHAVE}

Violações de Direitos. Questão Social. Crianças e Adolescentes.

\section{ABSTRACT}

This article aims to analyze the types of violations of rights served in CRAS and CREAS of the State of Pernambuco, in the case of children and adolescents. For

* Assistente Social. Mestranda pelo Departamento de Pós-Graduação em Serviço Social da Universidade Federal de Pernambuco. Av. Prof. Moraes Rego, 1235, Cidade Universitária, Recife (PE), CEP.: 50670-901. E-mail: <nathaliasantana91@hotmail.com>.

** Assistente Social. Mestranda em Serviço Social pelo Departamento de Pós-Graduação em Serviço Social da Universidade Federal de Pernambuco. Av. Prof. Moraes Rego, 1235, Cidade Universitária, Recife (PE), CEP.: 50670-901. E-mail: <elisacelinamelo@hotmail.com>. 
such a reflection, a bibliographical revision was necessary on the categories: social question, State, rights and social policy, in addition to the reintroduction of the norms, laws and policies in force in Brazil, in particular in Pernambuco on the aforementioned users. Also in this occasion, the data were extracted from the annual worksheets on the monthly reports of CRAS and CREAS consultations in 2016 on the website of the Ministry of Social Development and Fight against Hunger - MDS. It is worth noting that despite the advances made in the Federal Constitution of 1988 and the Statute of the Child and Adolescent in 1990, violations of rights committed against children and adolescents are still alarming.

\section{KEYWORDS}

Violations of Rights. Social Issues. Children and Adolescents.

Submetido em: 24/10/2017

Aceito em: 7/12/2017

\section{INTRODUÇÃO}

A exposição sobre a temática resulta da análise de indicadores extraídos em sua maioria da Secretaria de Avaliação e Gestão da Informação (SAGI), por meio do site do Ministério de Desenvolvimento Social e Combate à Fome (MDS) no que diz respeito aos dados quantitativos de atendimentos a crianças e adolescentes nas unidades de atendimentos referenciadas pela Política Nacional de Assistência Social (PNAS) (2004), no caso, objetivam-se nos Centros de Referência de Assistência Social (CRAS) e Centros de Referência Especializados de Assistência Social (CREAS).

No âmbito histórico, observa-se que as expressões da questão social construídas socialmente em meio ao sistema capitalista, peculiarmente, vivenciadas por crianças e adolescentes no Brasil, ainda recaem na contemporaneidade, mesmo diante de legislações que os denominam como sujeitos de direitos.

Em se tratando da Política Nacional de Assistência Social (PNAS), alguns pontos serão levantados, dentre eles, como estão pautados os serviços socioassistenciais na Região Nordeste, em consonância com o Sistema Único da Assistência Social (SUAS), por meio do sistema de Proteção Social voltado às famílias e indivíduos e sua relação com índices de atendimento a crianças e adolescentes.

A premissa é de analisar quais os indicadores de atendimentos referentes a crianças e adolescentes nos CRAS e CREAS no Estado 
de Pernambuco e como esses estão sendo conduzidos nos serviços socioassistenciais voltados para esse público, em conformidade com a PNAS (BRASIL, 2004).

Assim, sob o ângulo de um Estado pautado por tendências neoliberais, sobretudo, nas políticas sociais, a produção e reprodução das expressões da "questão social", assumem perfis historicamente particulares no cenário atual, especialmente para crianças e adolescentes, considerados o futuro do país.

\section{VIOLAÇÕES DE DIREITOS CONTRA CRIANÇAS E ADOLESCENTES: UMA BREVE CONTEXTUALIZAÇÃO}

Historicamente crianças e adolescentes foram e ainda são alvos de muitas intervenções. Inicialmente, no período colonial as crianças eram de interesse apenas das suas famílias e da Igreja Católica que as recolhiam, quando abandonadas nas Santas Casas de Misericórdia, motivada pela noção da caridade. Nesse contexto, de acordo com Rizzini (2011) a caridade com os pobres era um princípio da Igreja para a salvação da alma, então deveriam os fiéis ajudar os pobres que dependiam integralmente da caridade e cabia aos pobres serem agradecidos e submissos para demonstrar o reconhecimento.

Durante o século XVIII e parte do século XIX predominou a prática caritativa no cuidado com a criança e a principal forma de intervenção era o recolhimento, praticado principalmente pela Roda dos Expostos ${ }^{1}$. Ainda no século XIX, essa prática foi alvo de críticas diante dos debates sobre a higienização das cidades. As críticas partiam dos higienistas e dos moralistas, com relação aos higienistas, a crítica se detinha aos cuidados, pois era observado o alto índice de crianças que faleciam nesses espaços. De acordo com Rizinni (2011) os argumentos das críticas moralistas defendiam que as Casas dos Expostos incentivavam as práticas ilegítimas e imorais fora das relações legítimas, e o abandono das crianças.

$1 \mathrm{Na}$ Casa dos Expostos havia um artefato de madeira de forma cilíndrica, dividida ao meio por uma divisória chamada Roda dos Expostos, fixado ao muro ou janela da instituição no qual era depositada a criança, sendo que ao girar o artefato a criança era conduzida para dentro das dependências do mesmo. Puxava-se uma cordinha com uma sineta, para avisar a vigilante ou rodeira que um bebê acabava de ser abandonado e o expositor retirava-se do local, sem ter sua identidade revelada (MARCILIO, 2001). 
No final do séculoXIXeinício do séculoXX, diante das transformações econômicas, a criança é vista como o patrimônio da nação, para um futuro melhor. Essa passagem da caridade cristã para a lógica liberal da caridade laica segue as transformações econômicas, políticas e sociais que marcam a era industrial capitalista do século XIX, conforme Rizzini (2011) a infância adquire novos significados e uma dimensão diferente, tendo agora a obrigação de transformase em uma pessoa de bem, útil ao progresso e aos cofres da nação.

Diante do exposto, compreende-se que nesse período há uma aliança entre assistência e justiça:

É importante compreender o significado da aliança firmada entre Justiça e Assistência - uma associação cujos reflexos são claramente detectáveis no processo desenvolvido nas duas primeiras décadas do século XX e que deu origem á ação tutelar do Estado, legitimada pela criação de uma instância regulatória da infância - o Juízo de Menores e por uma legislação especial (ambos na década de 1920). Veremos que a Justiça e a assistência buscam na aliança a auto - sustentação pela complementação de suas ações. Ambas inserem-se na lógica do modelo filantrópico, que visava o saneamento moral da sociedade a incidir sobre o pobre. Tornam-se politicamente viáveis ao servir a função regulatória de enquadrar indivíduos, desde a infância, à disciplina e ao trabalho (RIZZINI, 2011, p. 125).

Segundo, Silva (2004), o Estado que se formou no Brasil nos anos 1930 foi embasado em teorias que vieram do exterior, especialmente da Europa e Estado Unidos. Tinha-se como objetivo igualar a realidade brasileira ao desenvolvimento civilizado dos grandes centros.

convive-se com um fenômeno que toma grandes proporções ao longo do tempo, sendo algo distinto da pobreza já existente o pauperismo das massas trabalhadoras que retratava o crescimento da pobreza em decorrência do aumento da capacidade da sociedade em produzir cada vez mais bens e serviços. "Assim, quando os trabalhadores tomam a iniciativa de reagir às condições de vida geradas a partir do pauperismo surge à denominada questão social como acontecimento da industrialização que surgia em pleno século XIX” (BISPO, 2009, p. 2). 
Registrava-se no País uma intensificação do processo de industrialização e um avanço significativo rumo ao desenvolvimento econômico, social, político e cultural. Esse avanço industrial concentra a classe trabalhadora nas áreas urbanas, tendo nesse processo o agravamento das condições de vida dos trabalhadores com um diferencial das condições vividas anteriormente, pois estas estavam relacionadas às condições materiais de desenvolvimento da sociedade enquanto que a questão social se dá a partir da relação política, econômica e social da contradição entre capital e trabalho.

Nesse período as crianças e adolescentes pertencentes às classes empobrecidas eram tratadas como uma ameaça à sociedade, fazendo com que o Estado realizasse algumas regulamentações que embora sob o discurso da proteção, culpabilizavam as famílias e as crianças.

Posteriormente, observa-se à publicação do Código de Menores, que expressava as demandas da chamada política de assistência e proteção aos menores. O contexto político, de acordo com Rizzini (2011), eradominadopor uma elite de formaçãopredominantemente jurídica estabelecia um paradoxo ao qual desejava fazer: educar o povo, porém garantindo as regalias da elite, além de instruir e capacitar para o trabalho, mediante vigilância e controle.

O Código de Menores de 1929, segundo Padilha (2006) inaugura o Paradigma da proteção irregular, que elegia unicamente a família como responsável pelo "menor", desvincula-a do seu contexto social e acabou por considerá-la como responsável pelo problema, da criança e do adolescente sem que o Estado assumisse sua proteção através de programas e políticas sociais.

Em dezembro de 1964 foi criada A Fundação Nacional do BemEstar do Menor (FUNABEM) que modelou a criação das Fundações Estaduais do Bem-Estar do Menor (FEBEM's). O surgimento da FUNABEM implicou na formação de uma Política Nacional de BemEstar do Menor que demarcou efetivamente a transição entre o código de Menores de 1927 e o Código de 1979. Todas as entidades públicas e privadas que prestavam atendimentos à criança e ao adolescente deveriam estar submetidas à Política Nacional do BemEstar do Menor (PNBEM). Segundo Padilha (2006), a FUNABEM 
foi criada para ter autonomia financeira e administrativa, para tal incorporou a estrutura do Serviço de Atendimento ao Menor(SAM) existente nos Estados, incluindo os atendimentos aos carentes e abandonados bem como aos infratores.

O Brasil estava completamente na contramão do movimento internacional, pois apesar dos anseios e da mobilização popular pela democratização do país e reconhecimento de atenção especial para as crianças, no final dos anos 70, o Código de Menores reformulado em 1979, de acordo com Silva (2005) era uma representação dos ideais dos militares. Segundo Padilha (2006) o novo código adotava expressamente o princípio da "Situação Irregular", que apesar de existir não estava explícito no Código de Menores 1927, esse paradigma focalizou os problemas das crianças e adolescentes como patologia social.

O Código de Menores, tanto não correspondia aos questionamentos que as forças políticas e a sociedade civil faziam, quanto não representavam as crianças e adolescentes, que continuavam sendo submetidos ao Juiz de Menores e confinados nessas instituições.

Essa correlação de forças fez com que o paradigma de Situação Irregular entrasse em colapso e surgisse o paradigma da Proteção Integral. De acordo com Silva (2005) era cada vez mais evidente que se estabelecia um consenso entre sociedade civil, movimentos sociais e o Estado sobre a falência deste paradigma e a necessidade de uma nova perspectiva para crianças e adolescentes, o que representa embate de classes para que seja definido a que caminho será guiado esse novo projeto.

Instituições internacionais como o Fundo das Nações Unidas para a Infância (UNICEF) faziam críticas ao Código, financiavam e estimulavam práticas alternativas comunitárias com meninos e meninas de rua, que posteriormente deram origem ao Movimento Nacional de Meninos e Meninas de Rua, movimento social no qual, segundo Silva (2005) emergia força política e social no tencionamento sobre a formulação do Estatuto da Criança e do Adolescente.

As principais críticas feitas ao Código e ao seu paradigma estavam no fato de este considerar que o "menor" deveria ser punido pela 
“situação irregular", enquanto que na verdade a situação daquelas famílias era uma expressão das desigualdades causadas pelo modo de produção da sociedade vigente. A segunda crítica estava no tratamento dado ao "menor" infrator, tido como "delinquente", no qual não existiam processos legais. Silva (2005) interpreta que “[...] nesse sentido, era 'regulamentada' a criminalização da pobreza" (SILVA, 2005, p. 33).

A questão social tem maior visibilidade com o fim da repressão, proporcionando um campo fértil para o desenvolvimento dos movimentos sociais, que com poder de pressão almejam legitimar suas demandas possibilitando maior visibilidade à assistência social ao lado das demais políticas públicas como estratégia privilegiada de enfrentamento da questão social, objetivando a diminuição das desigualdades sociais.

A década de 1980 foi um período de efervescência política e social, que culminou em grandes avanços sociais no país, que culminam no importante processo da promulgação da Constituição Federal de 1988.

A Constituição Cidadã incorpora reivindicações de vários segmentos da sociedade, alguns vão ter suas regulamentações especificas logo em seguida como as crianças e adolescentes com o Estatuto de Criança e do Adolescente (ECA) e outras terão um pouco mais tarde, a depender do movimento de correlação de forças.

Em 1990 é promulgado o ECA, que se fez em um momento singular, a conjuntura da época e as declarações e acordos internacionais sobre a criança e o adolescente, que vinham sendo firmados desde a década de 50, foram impulsionadores para a implementação do Estatuto.

Assim, o ECA nasceu em resposta ao esgotamento histórico- jurídico e social do Código de Menores de 1979. Nesse sentido o Estatuto é processo e resultado por que é uma construção histórica de luta sociais dos movimentos pela infância, dos setores progressistas da sociedade política e civil brasileira, da 'falência mundial' do direito e da justiça menorista, mas também é expressão das relações globais internacionais que se reconfiguravam frente ao novo padrão de gestão de acumulação flexível do capital. É nos marcos do 
neoliberalismo que o direito infanto-juvenil deixa de ser considerado um direito 'menor', 'pequeno', de criança para se tornar um direito 'maior', equiparado ao adulto (SILVA, 2005, p. 36).

Considerando a criança enquanto sujeito de direitos o ECA, inaugura o paradigma da Proteção Integral. A proteção social a partir do ECA sofre uma considerável mudança, que vem reafirmar o novo condicionamento dado as políticas e ações governamentais, que visam, primordialmente, o bem-estar das crianças e adolescentes.

O Estatuto estabelece o Sistema de Garantia de direitos que é a articulação entre as políticas sociais e sua fazendo parte deste sistema a entidades e órgãos que atuam na promoção, defesa e controle dos direitos das crianças. No reordenamento institucional promovido pelo Estatuto, duas diretrizes influenciam no funcionamento do Sistema de Garantia de direitos, são elas: a municipalização e a corresponsabilidade entre governo e sociedade civil. Os municípios passam a ter maior responsabilidade sobre as políticas para a infância e a elaboração e execução além do acompanhamento das políticas deve ser compartilhada pelo governo e sociedade civil (BRASIL, 1990).

O Sistema de Garantia de Direitos apresenta três eixos. O eixo da promoção é responsável pelo atendimento direto dos direitos da criança e do adolescente e compreende os serviços públicos nas áreas de educação, saúde e assistência social, entre outras, e as instituições não governamentais que também ofereçam atendimento à população infanto-juvenil, como creches e abrigos. $\mathrm{O}$ eixo da defesa, que atua na responsabilização de não cumprimento ou violação dos preceitos do ECA. E o eixo do controle social, que envolve as instituições responsáveis pelo acompanhamento, vigilância e avaliação do sistema de garantias.

Embora esse processo tenha garantido boa parte das demandas da época, não podemos considerar que essas garantias foram efetivadas. A economia mundial passava por um reordenamento econômico, no qual não era mais considerado necessário que - Estado tivesse participação na garantia das condições de reprodução na classe trabalhadora. O Estado interventor passa a ser considerado muito oneroso, devendo ser mínimo para o social. 
Desta forma surge o neoliberalismo apoiado nas ideias de Hayek. Segundo Montaño e Duriguetto (2011) a inserção do neoliberalismo no Brasil faz com que os direitos garantidos na Constituição Federal, não sejam efetivados. As garantias constitucionais não possuíam regulamentação expressa, portanto as regulamentações já foram desenvolvidas sobre os ideais neoliberais.

Assim, essa análise busca compreender que as políticas sociais não podem ser dissociadas das determinações econômicas. Portanto, certifica-se que é importante situar a infância no Nordeste a partir da discussão da questão regional (e estadual), particularizando a violação dos direitos no âmbito da política da Assistência Social, que está inserida no eixo da promoção dos direitos da criança e do adolescente e pelo caráter de acompanhamento territorial desta política.

\section{A POLÍTICA DE ASSISTÊNCIA SOCIAL E O SISTEMA DE PROTEÇÃO SOCIAL: PARTICULARIZANDO OS SERVIÇOS SOCIOASSISTENCIAIS NO NORDESTE}

Conforme Sposati (2009), estruturar o sistema da rede de proteção social "[...] significa prevenção, o que supõe a redução de fragilidade aos riscos, que podem ser permanentes ou temporários, e que passam a fazer parte do exame da questão do enfrentamento de riscos sociais" (SPOSATI, 2009, p. 21). Neste sentido, a Política Nacional de Assistência Social (PNAS) sistematiza a proteção social enquanto política garantidora da segurança de sobrevivência (de rendimento e autonomia); de acolhida; e, de convívio ou vivência familiar (BRASIL, 2004).

A proteção social pressupõe, de acordo com Jaccoud, Silva e Beghin (2009), tomar a defesa de algo, impedir sua destruição, sua alteração. A ideia de proteção contém um caráter preservacionista - não da precariedade, mas da vida -, requer apoio, guarda, socorro e amparo. Esse sentido preservacionista é que exige tanto a noção de segurança social ${ }^{2}$ como a de direitos sociais ${ }^{3}$.

\footnotetext{
2 A Declaração Universal dos Direitos do Homem, em 1948, afirma que toda a pessoa tem direito à segurança social ( $\left(\operatorname{rrt}^{\circ}{ }^{\circ} 2^{\circ}\right.$ ) e enuncia que esse direito geral se traduz no direito à assistência médica e serviços sociais necessários, no direito à segurança social no caso de desemprego, doença, invalidez, viuvez, velhice e perda de meios de subsistência (art. $\left.{ }^{\circ} 25^{\circ}\right)$.

3 De acordo com a Constituição Federal de 1988 (BRASIL, 1988), no Capítulo II, Art. $6^{\circ}$ São direitos sociais a educação, a saúde, a alimentação, o trabalho, a moradia, o lazer, a segurança, a previdência social, a proteção à maternidade e à infância, a assistência aos desamparados.
} 
No caso brasileiro, o sistema de proteção social, de acordo com Jaccoud, Silva e Beghin (2009) está organizado em três pilares. O primeiro é constituído pela política de previdência social, que tem caráter predominantemente contributivo. O segundo pilar da seguridade social é a política de saúde, caracterizada pelo acesso universal e regida pelos princípios da equidade e da integralidade, implementada pormeio do Sistema Único de Saúde(SUS). O terceiro pilar é constituído pela Política de Assistência Social, de caráter não contributivo e acessível a todos os que dela necessitarem.

O conteúdo da Assistência Social se materializa como um pilar do Sistema de Proteção Social Brasileiro, no âmbito da Seguridade Social, a partir da Resolução $n^{\circ}$ 145, de 15 de outubro de 2004 que aprovou a Política Nacional de Assistência Social (PNAS). Segundo a NOB/SUAS:

A proteção social de Assistência Social consiste no conjunto de ações, cuidados, atenções, benefícios e auxílios ofertados pelo SUAS para redução e prevenção do impacto das vicissitudes sociais e naturais ao ciclo da vida, à dignidade humana e à família como núcleo básico de sustentação efetiva, biológica e relacional (BRASIL, 2005, p. 16 apud BRASIL, 2004).

Assim, conforme descrito na PNAS (BRASIL, 2004) o SUAS visa garantir a proteção social para os cidadãos a que dela venham necessitar, em conformidade com a proposta da PNAS (BRASIL, 2004), que aponta os níveis de proteção social: básica e especial, tendo como direção o desenvolvimento humano e social e os direitos de "cidadania".

Ainda, com relação à proteção social, a PNAS (BRASIL, 2004)assinala a matricialidade sociofamiliar, como eixo central, compreendendo que a família é uma instituição mediadora "[...] das relações entre os sujeitos e a coletividade, delimitando, continuamente os deslocamentos entre o público e o privado, bem como geradora de modalidades comunitárias de vida" (BRASIL, 2004, p. 90). Nesse sentido, os programas e serviços deverão ser direcionados para o atendimento à família, reforçando-a enquanto um dos pilares da rede de proteção social. 
Contudo, é notório que esse sistema organizado de proteção social não se constituiu como resposta imediata às demandas da população. Estes resultam de lutas e embates políticos no campo da assistência social que garantiram condições políticas e institucionais para que esta se apresentasse enquanto um direito de "cidadania". É o que se exemplifica com a seguinte passagem,

[...] os modernos sistemas de proteção social não são apenas respostas automáticas e mecânicas às necessidades e carências apresentadas e vivenciadas pelas diferentes sociedades. Muito mais do que isso, eles representam formas históricas de consenso político, de sucessivas e intermináveis pactuações que, considerando as diferenças no interior das sociedades, buscam, incessantemente, responder a pelo menos três questões: quem será protegido? Como será protegido? Quanto de proteção? (SILVA; YASBEK; GIOVANNI, 2004, p. 16).

À vista do exposto por Jacooud, Silva e Beghin (2009), a proteção social, no Brasil, trata duas formas de atenção, sendo elas: os benefícios e os serviços. O primeiro se refere à transferência em espécie fora da relação de trabalho ou da legislação social do trabalho para atender a determinadas situações de vulnerabilidade, operando como substitutivo ou complementarmente à remuneração vinda da ocupação/renda da família. O segundo se refere a um conjunto de atividades prestadas em um determinado local de trabalho que se destinam a prover determinadas atenções, desenvolver procedimentos com e para pessoas, afiançar aquisições. Os serviços produzem bens e se caracterizam em modalidades, a partir desses bens, que atendem a determinadas necessidades com esse objetivo.

No que se refere aos níveis de proteção social a PNAS (BRASIL, 2004, p. 33-36), afirma que deve ser assegurada:

A Proteção Social Básica, prevenindo situações de risco por meio do desenvolvimento de potencialidades e aquisições, bem como o fortalecimento de vínculos familiares e comunitários. Sendo destinada à população que vive em situação de vulnerabilidade social decorrente da pobreza, privação e, ou, fragilização de vínculos afetivos. 
A Proteção Social Especial, que é modalidade de atendimento assistencial destinada a famílias e a indivíduos que se encontram em situação de risco pessoal e social, por decorrência de abandono, maus-tratos físicos, e/ou psíquicos, abuso sexual, uso de substâncias psicoativas, cumprimento de medidas socioeducativas, situação de rua, situação de trabalho infantil, entre outras. A Proteção Social Especial está dividida em dois níveis de complexidade: a média e a alta complexidade. A execução dos serviços ligados à Proteção Social Especial requer acompanhamento individual e a construção de soluções protetivas (BRASIL, 2004, p. 33-36).

A execução da proteção social se materializa, através das unidades públicas estatais denominadas dos CRAS e Centros de Referência Especial da Assistência Social (CREAS), que são unidades públicas de base municipal ou regional, situados em áreas de risco social, em que os serviços devem ocorrer de forma articulada com o Poder Judiciário, Ministério Público, Defensoria Pública, Conselhos Tutelares e outros serviços socioassistenciais, e outras políticas públicas, no intuito de estruturar uma rede efetiva de proteção social.

Além disso, a Proteção Social Especial está subdividida entre média e alta complexidade, sendo a média complexidade operacionalizada pelos CREAS e Centros de Referência Especializados a Pessoa em Situação de Rua - Centro POP e a alta complexidade compreende todos os serviços de acolhimento institucionais, sejam eles para adultos e/ou crianças e adolescentes.

Por sua vez, o total da população nordestina em situação de extrema pobreza (cadastradas no Cadúnico e com acesso aos benefícios do Programa Bolsa Família), de acordo com o SAGI/MDS (2016) é de 553.272 (quinhentos e cinquenta três mil e duzentos e setenta e dois), sendo estes que tiveram acesso aos direitos socioassistenciais, ao mesmo tempo em que não se observam os números daqueles em fila de espera e/ou que não foram contemplados.

De acordo com os indicadores trazidos pela Secretaria de Avaliação e Gestão da Informação/Ministério do Desenvolvimento Social e Combate à Fome (2016), no nordeste, temos o seguinte panorama 
dos serviços implantados com referência a Política Nacional de Assistência Social (BRASIL, 2004):

Quadro I - Serviços Socioassistenciais financiados pelo MDS - 2016

\begin{tabular}{|l|l|l|l|l|}
\hline $\begin{array}{l}\text { Estados da Região } \\
\text { Nordeste }\end{array}$ & No DE CRAS & No DE CREAS & $\begin{array}{l}\text { N}^{\circ} \text { DE CENTRO } \\
\text { POP }\end{array}$ & $\begin{array}{l}\text { Vagas para } \\
\text { Acolhimento } \\
\text { Institucional }\end{array}$ \\
\hline ALAGOAS & 136 & 57 & 4 & 125 \\
\hline BAHIA & 575 & 202 & 17 & 650 \\
\hline CEARÁ & 361 & 111 & 9 & 625 \\
\hline MARANHÃO & 307 & 122 & 8 & 275 \\
\hline PARAÍBA & 259 & 1 & 2 & 300 \\
\hline PERNAMBUCO & 326 & 158 & 9 & 500 \\
\hline PIAUÍ & 269 & 5 & 2 & 75 \\
\hline $\begin{array}{l}\text { RIO GRANDE DO } \\
\text { NORTE }\end{array}$ & 217 & 55 & 2 & 150 \\
\hline SERGIPE & 104 & 36 & 2 & 50 \\
\hline TOTAL GERAL & 2554 & 747 & 55 & 2750 \\
\hline
\end{tabular}

Fonte: SAGI/MDS (2016).

Observa-se que o número dos CRAS é bem superior aos demais serviços supracitados, totalizando na Região Nordeste 2.554. Vale ressaltar que na última pesquisa do IBGE (INSTITUTO BRASILEIRO DE GEOGRAFIA E ESTATÍSTICA, 2014) os dados apresentados indicam que, de 2009 para 2013, o número de CRAS passou de 5.499 em 4.032 municípios para 7.986 em 5.437 municípios. A Região Nordeste foi a que concentrou a maior proporção de municípios com CRAS (99,5\%), seguida do Centro-Oeste (98,7\%), Norte (97,6\%), Sudeste $(96,4 \%)$ e Sul $(96,1 \%)$.

Outro ponto relevante é o número de vagas para o acolhimento institucional com um total de 2.750 , um aspecto relevante é que o maior percentual de acolhimentos é entre crianças e adolescentes vítimas de violações de direitos (violência física, psicológica, abandono, maus tratos, dentre outros), segundo informações trazidas pelo Censo SUAS (BRASIL, 2017C).

Em se tratando do segmento criança e adolescente, verifica-se que nas unidades de atendimento CRAS, CREAS e Acolhimento Institucional, conforme os Relatórios Mensais de Atendimentos (RMA's) (BRASIL, 2017a), destes serviços, em especial nos CREAS, 
os indicadores de atendimentos são em sua maioria voltados para estes são públicos, ditos como prioritários. Nesses relatórios (RMA's) concentram-se o quantitativo de atendimentos, por blocos de serviços, segundo e perfil e segmentos atendidos.

De acordo com Tipificação Nacional dos Serviços Socioassistenciais (BRASIL, 2009), os CRAS e CREAS, enquanto unidades integrantes do SUAS, atuam justamente na prestação de serviços especializados e continuados a famílias e indivíduos na prevenção (no caso dos CRAS) e no atendimento das violações de direitos por ocorrência de: violência física, psicológica e negligência; Violência sexual: abuso e/ou exploração sexual; Afastamento do convívio familiar devido à aplicação de medida socioeducativa ou medida de proteção; Tráfico de pessoas; Situação de rua e mendicância; Abandono; Vivência de trabalho infantil; Discriminação em decorrência da orientação sexual e/ou raça/etnia; Outras formas de violação de direitos decorrentes de discriminações/submissões a situações que provocam danos e agravos a sua condição de vida e os impedem de usufruir autonomia e bem estar; Descumprimento de condicionalidades do PBF e do PETI em decorrência de violação de direitos.

Neste contexto para realizar esses atendimentos especificados, os CRAS e CREAS conforme a Tipificação Nacional de Serviços Socioassistenciais (BRASIL, 2009), dispõem dos seguintes serviços:

\section{Quadro II - Serviços de Atendimentos nos CRAS e CREAS}

\begin{tabular}{|l|l|}
\hline SERVIÇOS NO CRAS & SERVIÇOS NO CREAS \\
\hline $\begin{array}{l}\text { - Serviço de Proteção e Atendimento Integral à } \\
\text { Família e Indivíduos (PAIF) }\end{array}$ & $\begin{array}{l}\text { - Serviço de Proteção e Atendimento Especiali- } \\
\text { zado a Famílias e Indivíduos (PAEFI) }\end{array}$ \\
\hline $\begin{array}{l}\text { - Serviço de Convivência e Fortalecimento de } \\
\text { Vínculos - SCFV }\end{array}$ & $\begin{array}{l}\text { - Serviço de Proteção Social a Adolescentes em } \\
\text { Cumprimento de Medida Socioeducativa de Li- } \\
\text { berdade Assistida (LA), e de Prestação de Servi- } \\
\text { ços à Comunidade (PSC); }\end{array}$ \\
\hline $\begin{array}{l}\text { - Serviço de Proteção Social Básica no Domicílio } \\
\text { para Pessoas com Deficiência e Idosas, }\end{array}$ & - Serviço de Abordagem Social; \\
\hline & $\begin{array}{l}\text { - Serviço de Proteção Social Especial para Pes- } \\
\text { soas com Deficiência, Idosas e suas Famílias. }\end{array}$ \\
\hline
\end{tabular}

Fonte: Criado pelas autoras, com base na Tipificação Nacional dos Serviços Socioassistenciais (BRASIL, 2009).

Em se tratando dos serviços especificados no Quadro II, compreendem que as atenções são direcionadas para a 
promoção de direitos, preservação de vínculos sociofamiliares e fortalecimento da função protetiva da família diante do conjunto de condições que as vulnerabilizam e/ou as submetem a situações de risco pessoal e social.

Assim, a Política de Assistência Social, se materializa em consonância com as unidades de atendimentos e os serviços prestados, ao mesmo tempo em que no Brasil, em particular no Nordeste, percebe-se a crescente expansão de políticas públicas voltadas para "amenizar" as condições gerais de vida dos mais "vulneráveis", uma vez que "[...] quando os direitos são conquistados e regulados na forma da lei, isso não significa a superação nem da desigualdade social nem das formas de opressão vigentes da vida cotidiana" (BERING; SANTOS, 2009, p. 280).

\section{OS INDICADORES DE ATENDIMENTOS A CRIANÇA E AO ADOLESCENTE NO ESTADO DE PERNAMBUCO}

Em Pernambuco, ao se fazer uma análise dos indicadores de violações de direitos extraídos dos RMA's atendidos pelos CRAS e CREAS no ano de 2016, destaca-se a existência de um quantitativo significativo de casos que envolvem Crianças e Adolescentes vítimas de violência/ violação de direitos, como o trabalho infantil, o abuso e exploração sexual de crianças e adolescentes, a negligência e o abandono e a violência física e psicológica.

No que diz respeito à violência, na Declaração Universal dos Direitos Humanos, (ORGANIZAÇÃO DAS NAÇÕES UNIDAS, 2009) art. 3 tem-se que "[...] todo ser humano tem direito à vida, à liberdade e à segurança pessoal [...]”, em se tratando da criança e do adolescente o ECA (1990) estabelece prioridade nas políticas públicas nos atendimentos voltados para esse público.

Tomando como referência o Ministério de Desenvolvimento Social e Combate à Fome (MDS), o termo "trabalho infantil" refere-se às atividades econômicas e/ou atividades de sobrevivência, com ou sem finalidade de lucro, remuneradas ou não, desempenhadas por crianças ou adolescentes em idade inferior a 16 (dezesseis) anos, ressalvada a condição de aprendiz a partir dos 14 (quatorze) anos, independentemente de sua condição ocupacional. 
No Estado de Pernambuco, o Trabalho Infantil, ainda afeta inúmeras crianças e adolescentes, no entanto de acordo com os dados estatísticos do IBGE (2010) houve uma considerável diminuição desse índice de 1.883 .85 (2000) para 1.478 .65 (2010) encontrandose em $9^{\circ}$ lugar no ranking nacional com crianças e adolescentes em situação de Trabalho Infantil.

Conforme Dados do Disque 100 - Vinculado ao MDS, no ano de 2014 foram registradas 67.831 denúncias de negligência onde a maioria se refere a desamparo e falta de responsabilização envolvendo crianças e adolescentes. Apesar de se apresentar menos cruel que a violência física, esse tipo de violação abre caminho para outras situações, como por exemplo, maus-tratos, agressões, abuso sexual e até levar a morte. É de extrema importância salientar que foi mais expressiva que a violência sexual, psicológica e física.

Os Planos Municipal e Estadual são instrumentos de defesa dos direitos de crianças e adolescentes, a fim de criar, fortalecer e implementar um conjunto articulado de ações e metas fundamentais para assegurar a proteção integral à criança e ao adolescente vitimas de violência sexual, bem como vítimas de trabalho infantil.

Diante do exposto, em 2001, o governo brasileiro implantou o Programa "Sentinela", que tinha como objetivo atender crianças e adolescentes vítimas de violência sexual e suas famílias e lançou o Plano Nacional de Enfrentamento à Violência Sexual de Crianças e Adolescentes, o qual estabelecia diretrizes de atendimento às vítimas.

Em Pernambuco, esta ação foi implantada em 24 municípios, e a partir de 2005, foi implementada e ampliada para 76 municípios, hoje, esse atendimento é uma política pública ratificada pela Política Nacional de Assistência Social/PNAS-2004 e NOB/SUAS-2005. O atendimento é realizado em Centros de Referência Especializados da Assistência Social (CREAS), norteados pelos Planos Municipal e Estadual, a partir dos seguintes eixos estratégicos: Análise da Situação, Atendimento Integral, Defesa e Responsabilização, Formação e Qualificação, Prevenção, Mobilização e Comunicação, Protagonismo Infanto-juvenil. 
Diante desse contexto, salienta-se o panorama pernambucano, que possui 184 municípios, uma população estimada de 1.221.174 em situação de extrema pobreza4 ${ }^{4}$, segundo o Censo do IBGE (2010), destas $563.664(46,1 \%)$ são crianças e adolescentes. Assim, no que se refere ao atendimento a crianças e adolescentes, o Estado de Pernambuco, conta atualmente com (vide Quadro I): 326 CRAS; 158 CREAS; 9 Centros POP e 500 vagas nas Casas de Acolhimento Institucional.

Particularizando os atendimentos nos CRAS, no que se refere a crianças e adolescentes, tem-se:

Gráfico 1- Dados dos atendimentos realizados pelos Centros de Referência e Assistência Social (CRAS) no ano de 2016 em Pernambuco

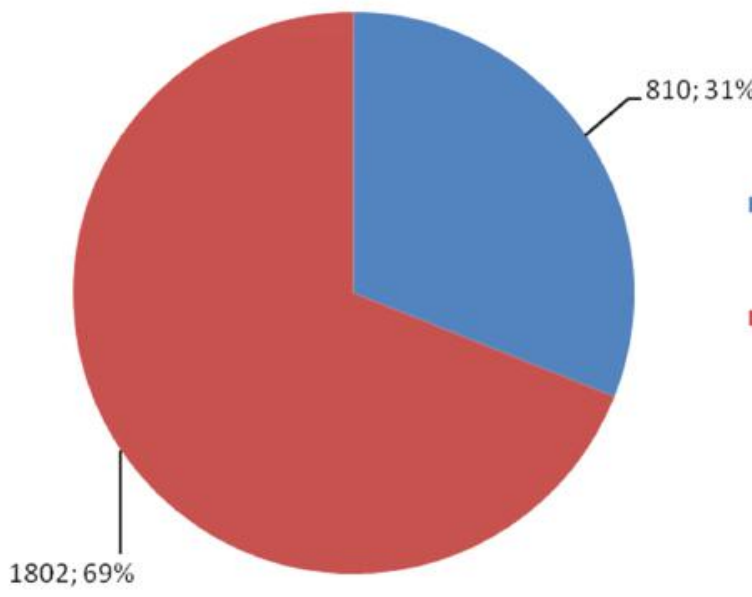

- Familias com crianças ou adolescentes em Serviço de Acolhimento

- Familias com crianças ou adolescentes em situação de trabalho infantil

Fonte: Criado pelas autoras, com base nos dados dos Relatórios Mensais de Atendimentos (RMA's) dos CRAS de Pernambuco do ano de 2016, disponíveis no SAGI/MDS/RMA (2016).

Percebe-se que os dados de trabalho infantil ainda assombram os municípios pernambucanos, mesmo diante de ações estratégicas no enfrentamento a essa violação. Outro ponto relevante é o número de crianças e adolescentes encaminhadas para os serviços

4 Segundo Rocha (2003) a pobreza absoluta (extrema pobreza) está estreitamente vinculada às questões de sobrevivência física, ao não atendimento das necessidades vinculadas ao mínimo vital. 
de acolhimento institucional, levando em consideração que em 2016 só havia 500 vagas, ultrapassando em 62\% o número de vagas suficientes.

No que diz repeito, aos atendimentos do Serviço de Convivência e Fortalecimento de Vínculos, os CRAS em 2016 atenderam 610.592 crianças e adolescentes em seus espaços, vale salientar, que alguns municípios estabelecem convênios com Organizações Não Governamentais para a execução "indireta" desse serviço, sendo estes acompanhados pelos técnicos de referência dos CRAS (assistentes sociais e psicólogos).

Em relação ao quadro de atendimentos realizados nos CREAS no ano de 2016 observa-se:

\section{Gráfico Gráfico2 - Dados e Indicadores dos atendimentos realizados pelos Centros de Referência Especializados de Assistência Social (CREAS) no ano de 2016 em Pernambuco}

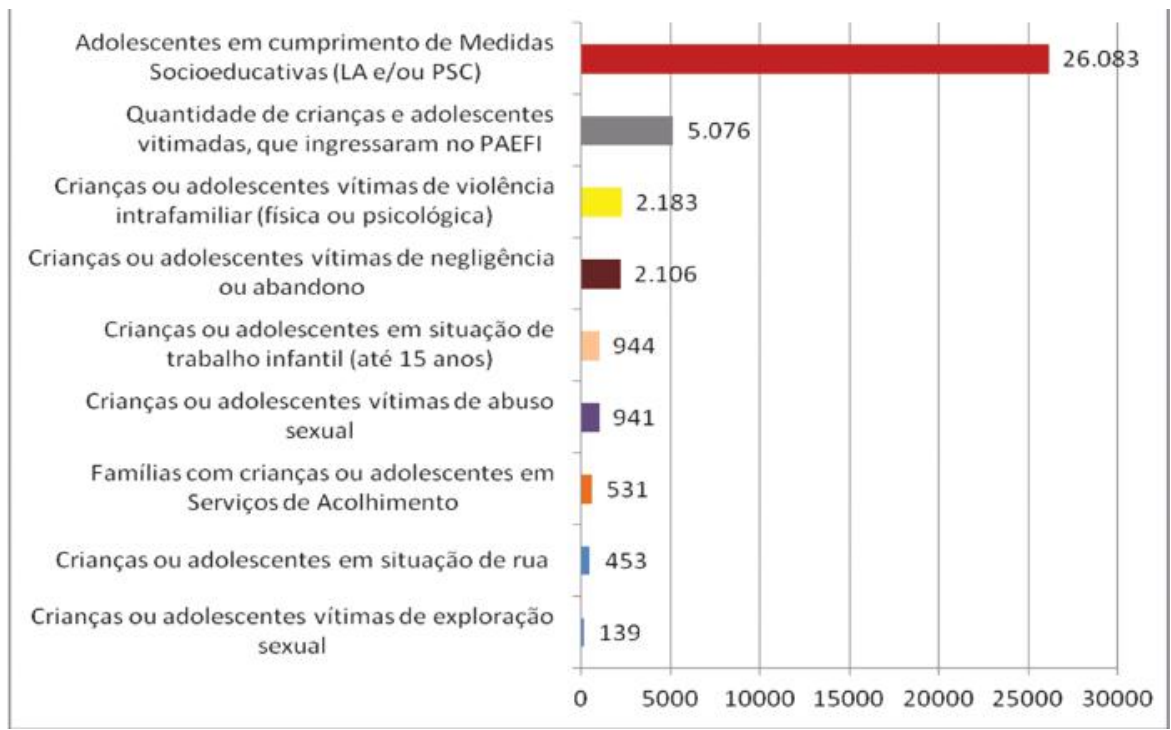

Fonte: Criado pelas autoras, com base nos dados dos Relatórios Mensais de Atendimentos - RMA's dos CREAS 2016, disponíveis no SAGI/MDS/RMA (2016).

Os dados acima revelam substancialmente que crianças e adolescentes dentro do Estado de Pernambuco são alvos dos piores tipos de violência, e acima de tudo, estão inseridos num contexto social e jurídico, no que tange o acometimento de atos infracionais, 
o gráfico apresenta um total de 26.083 casos executados nos CREAS, por meio do Serviço de Medida Socioeducativa em Meio Aberto de Liberdade Assistida (LA) ou de Prestação de Serviço a Comunidade (PSC).

Em relação aos tipos de violações sofridas por esse segmento, sendo física e/ou psicológica, os familiares são os maiores vetores que as praticam, conforme ilustra o indicador "intrafamiliar", além disso, em sua maioria, os casos são encaminhados para as unidades de atendimento, através do Sistema de Garantia de Direitos - Conselho Tutelar, Ministério Público e Vara da Infância e Adolescência dos municípios e/ou comarcas de referência.

Um ponto relevante em relação às crianças e adolescentes é de como esses atendimentos são realizados e acompanhados, uma vez que em sua maioria, os equipamentos da assistência social disponíveis no território Pernambuco (CRAS e CREAS), que prestam atendimentos socioassistenciais não dispõem de recursos humanos e materiais suficientes.

De acordo com os Índices de Desenvolvimento do CRAS e CREAS (IDCRAS e IDCREAS), em 2016, Pernambuco num contexto geral obteve uma média de 3 (três) pontos nos serviços supracitados, significa que ainda atende com o mínimo exigido de equipes técnicas de referência; de infraestrutura e de execução e articulação dos serviços.

Assim, corroborando com França e Ferreira (2016):

[...] a materialização da ação do Estado na proteção social a famílias com crianças e adolescentes, apesar de apresentar avanços em seus formatos normativos e institucionais, ainda carece de uma abordagem mais ampliada da questão social e da multiplicidade dos problemas que ela efetivamente apresenta (situação de pobreza e/ou de rua, trabalho infantil, violências, exclusões, etc.), em face do acirramento do sistema capitalista (FRANÇA; FERREIRA, 2016, p. 59).

Por fim, a realidade apresentada remete a reflexões sobre a efetividade das estratégias das políticas públicas, em especial, da política de assistência social, principalmente para crianças e adolescentes, enquanto mecanismos políticos de enfrentamento 
das problemáticas sociais geradas pelas contradições do sistema capitalista, que nos faz adentrar num universo de indagações recheado de contradições e ambivalências.

\section{CRIANÇAS E ADOLESCENTES: SUJEITOS DE DIREITOS?}

A luta por garantia e reconhecimento dos direitos é importante, porém insuficiente perante os desafios impostos em uma sociedade de classes. As leis apenas reconhecem as demandas a partir da luta de classe, mas não é capaz de cessar os desafios inerentes a essa sociabilidade.

Abordando o direito apenas na esfera do próprio direito, assumese que os fatos ali abordados são irredutíveis e imutáveis, assim a esfera jurídica é compreendia socialmente como soberana e isenta. Na sociedade capitalista, de acordo com Lukács (2013) o direito é uma esfera de afirmação do modo de produção, uma forma de conservação. O direito não considera as bases sociais e materiais das relações, estabelece uma igualdade apenas jurídica.

A conquista e garantia jurídica do direito não significa que a sociedade pode conformar-se com o direito reconhecido e ir à busca de outros, esse movimento de fato acontece, vão-se em busca de outros direitos, porém não de forma conformada. De acordo com Gomes (2007) o direito adquirido continua sendo pauta de defesa da sociedade civil organizada e dos movimentos sociais, por que a garantia formal não significa a garantia material e em momentos de crise e avanço do conservadorismo são os direitos sociais os primeiros a serem atacados.

De acordo com Lessa (2015) após Marx e Engels, Lukács (2013) postula que o direito se constituiu como um complexo a partir do surgimento da sociedade baseada na exploração do homem, onde os conflitos sociais são antagônicos. Dessa forma, o direito é necessário para regular os conflitos e garantir a ordem social.

Portanto, Lukács(2013)ponderaqueodireitonãosurgenaturalmente das relações entre os homens e sim da complexificação das suas relações e com a sociedade burguesa propriamente constituída coloca os homens uns contra os outros na estrutura das classes.

De acordo com Engels e Kautsky (2012), o surgimento da categoria "sujeito de direito" possibilita que o homem entre no mercado 
enquanto mercadoria fundamental para o modo de produção. A liberdade operada pelo direito, nada mais é do que a disponibilidade do homem em relação ao mercado, enquanto dono de sua própria mercadoria.

A luta de classes impulsiona que as necessidades da classe trabalhadora sejam reconhecidas e atendidas. O Estado por sua vez as reconhece e intervém, porém é importante considerar que as demandas da classe trabalhadora são inerentes ao modo de produção capitalista e apesar do direito também ter sua gênese na sociedade capitalista, seus objetivos são antagônicos, pois o segundo não é uma necessidade universal do gênero humano, mas sim em necessidades peculiares às sociedades de classe.

Falar dos direitos de crianças e adolescentes na sociedade capitalista não é só compreender a defesa da promoção, do cuidado e da defesa de um segmento populacional em fase de desenvolvimento biológico, psíquico e social. Estamos falando fundamentalmente da reprodução da força de trabalho, neste contexto as crianças e adolescentes precisam ser direcionadas para os interesses do capital, em alguns momentos essa reprodução está mais próxima do Estado, ou seja, este executa mais ações. São nos momentos em que o capital precisa formar mão-de-obra para se instalar ou ampliar mercado. O processo de desmonte das políticas públicas a partir do neoliberalismo faz com que essas não se efetivem e, portanto, o Sistema de Garantia de direitos não é efetivado embora esse seja legitimado por ter suas instituições.

O reconhecimento de crianças e adolescentes como sujeitos de direitos se faz diante de muitas contradições. Atualmente podemos observar que o avanço do conservadorismo desqualifica e moraliza as expressões da questão social, em momentos de crises e ameaça de direitos o primeiro debate que vem a tona é a redução da maioridade penal, sempre arraigada de culpabilização das famílias e dos sujeitos, hostilidade com os militantes da defesa dos direitos humanos e principalmente o completo afastamento das causas concretas da violência e o papel do Estado, é sempre de silêncio conveniente, normalmente a mídia encabeça junto com os setores mais conservadores da sociedade. 
De acordo com Lukács (2013) o direito não traz consigo o caráter de transformador da sociedade, nem de supressão do modo de produção, o mesmo apresenta por seu caráter contraditório, a possibilidade de reconhecer juridicamente lutas e conquistas da classe trabalhadora. Salienta-se, tendo em vista que este é um meio do homem garantir condições mínimas para sua reprodução na sociedade capitalista, sem deixar de deslumbrar um horizonte societário diferente do capitalismo.

Por maior que sejam as possibilidades do ECA em garantir direitos e participação social, suas bases são fincadas no processo de reprodução de dominação social. Assim, prevalecem os interesses dos grupos hegemônicos que compõe a luta de classes e implementarão suas ações a partir das formas conquistadas por eles na legislação, adentrando nos aspectos que inicialmente mostravam-se apenas favoráveis a classe trabalhadora.

O ECA traz várias inovações quanto à gestão, método e conteúdo para as questões da criança e do adolescente, promovendo democratização e parcerias entre o Estado e a sociedade, além da municipalização dos serviços.

Observa-se que o avanço conservador penetra de uma forma geral em todo o Sistema de Garantia de Direitos, as esferas da política servem de jogo de interesses, sofrem intervenções políticas partidárias e religiosas. Conforme já sinalizado o caráter do direito não é romper com a base social e, portanto, pode-se compreender que o Estatuto da Criança e do Adolescente, embora represente descontinuidade do paradigma anterior, traz consigo algumas continuidades, como por exemplo, o conservadorismo que está na contradição inerente à base da sociedade capitalista.

No Brasil, "falar sobre direitos e sua relação com a totalidade da vida social pressupõe considerar os indivíduos em sua vida cotidiana, espaço-tempo em que as expressões da questão social se efetivam, sobretudo, como violações de direitos" (BERING; SANTOS, 2009, p. 276). O desenrolar das políticas sociais, voltadas para suprir as demandas trazidas pelo capital, denotam um possível enfretamento a vulnerabilidade social instaurada frente a um Estado de ideário neoliberal. 
Não se pretende aqui sinalizar que o direito por não ter caráter revolucionário não seja importante e que diante das ofensivas conservadoras deve-se ser pessimista. Ao contrário, exatamente pelo seu caráter contraditório, o direito, é sim uma estratégia muito importante para que se possa tencionar o modo de produção capitalista, no entanto, não se pode considera-lo como um limite nas pautas seja no fomento de políticas públicas ou na formulação das legislações e normativas.

\section{NOTAS CONCLUSIVAS}

Analisando as violações de direitos das crianças e adolescentes no Estado de Pernambuco, compreendemos que embora se tenha instituído o paradigma da Proteção Integral, este não consegue garantir efetivamente a proteção das crianças e adolescentes, sobretudo, a infância pobre, filha da classe trabalhadora, classe a qual vivencia cotidianamente as expressões da questão social e sofre as explorações da força de trabalho no modo de produção capitalista.

Os dados revelam que em grande parte das crianças e adolescentes em pobreza e extrema pobreza, consideradas público prioritário da Política de Assistência Social, ainda são vítimas e ao mesmo tempo culpabilizadas por atos cometidos contra a sociedade, ditos como "infracionais", cuja ligação está inteiramente no modo de "ser/ter" do capital, em que prevalecem os valores e "bons costumes" como regras.

Observa-se que as unidades de atendimentos que compõe a Política de Assistência Social desenvolvem programas, projetos e serviços que visam "amenizar" as situações vividas por essas famílias, neste sentido "[...] as políticas sociais e direitos sociais, políticos e trabalhistas representam também conquistas dos trabalhadores e setores subalternos, que podem diminuir, mas jamais eliminar as desigualdades [...]" (MONTAÑO, 2012, p. 285), uma vez que estas são inerentes ao sistema capitalista vigente.

Em se tratando dos dados sobre as violações de direitos, ainda são assombrosos, a exploração do trabalho infantil reflete a face perversa do capital, em que as famílias, por vezes não terem condições de sobrevivência acabam envolvendo suas crianças e 
adolescentes no trabalho para que minimamente, possam possa garantir sua produção/reprodução. O capital, por sua vez, se apropria dessa força de trabalho para garantir uma maior extração de mais-valor, pois crianças e adolescentes são considerados mão de obra de baixo custo.

É preciso compreender que na sociedade capitalista o que prevalece a exploração do homem pelo homem para a obtenção do desenvolvimento econômico, desta forma o trabalho infantil sempre será nesta sociabilidade uma questão de intervenção.

Em se tratando das violências, no Estado de Pernambuco observase um grande contingente de crianças e adolescentes vítimas das mais diversas, totalizando 5.076 casos, número que necessita ser problematizados, sobretudo, com relação as condições de vida das famílias e as formas de atuação desse Estado em relação a isso. A culpabilização das famílias sobre suas condições de vida esvazia do debate o papel do Estado em garantir o acesso dessas famílias às políticas públicas.

Outro ponto relevante, trazido pelos dados apresentados é a reflexão de como está o acompanhamento das unidades de atendimento CRAS e CREAS no território pernambucano, uma vez que, conforme os indicadores que estes não possuem recursos humanos e materiais suficientes para um atendimento e acompanhamento qualificado.

Pode-se dizer que compreender a criança e o adolescente como sujeitos de direitos significa ir à luta por direitos que as definam como detentoras de cuidados que possibilitem seu desenvolvimento psicológico, biológico e social.

Diante do universo apresentado apreende-se que o direito não apresenta um caráter revolucionário de superação das violações de direitos, pois estas são inerentes à sociedade de modo de produção capitalista e sua extinção, corroborando com os autores marxistas só será possível com a superação da ordem capitalista.

Neste sentido vale considerar que o Estatuto da Criança e do Adolescente não é revolucionário do ponto de vista da superação da ordem, pois uma legislação não modifica as bases de uma sociedade engessada pela capital, no entanto, o ECA é 
fundamental para estabelecer direitos a um segmento que está em desenvolvimento e que do ponto de vista da reprodução da sociedade capitalista precisa sim ter direitos reconhecidos para garantir essa reprodução. O que gera um novo ponto de disputa, o direcionamento oferecido pelas políticas voltadas para as crianças e adolescentes e seus desdobramentos a médio e longo prazo.

Por fim, identifica-se o ponto de maior disputa entre os dois projetos: o de concretizar direitos e trabalhar consciência política ou o de desmontar direitos e investir em subordinação, em suma o projeto proletário x projeto burguês.

Naperspectivahistórica, noquedizrespeitoa criançaseadolescentes percebe-se o quanto a luta de classes foi e é uma constante, é um movimento contínuo e que necessita de constante fortalecimento, a sociedade burguesa estabelece sempre estratégias de superar os ganhos da classe trabalhadora.

Assim, considera-se que as violações de direitos de crianças e adolescentes são as expressões da questão social que repercutem diretamente no desenvolvimento da classe trabalhadora e que este segmento está em constante disputa entre os projetos societários. Garantir o bem-estar de crianças e adolescentes significa lutar no campo do imediato sem perder o horizonte da superação da ordem capitalista, para que finalmente as violações de direitos sejam erradicadas.

\section{REFERÊNCIAS}

BERING, Elaine Rossetti; SANTOS, Silvana Mara de Morais dos. Questão Social e direitos. In:Serviço Social: Direitos Sociais e Competências Profissionais. CFESS. 2009, p. 276-280.

BISPO, Priscila. Questão Social, Políticas Sociais e Serviço Social no Capitalismo Monopolista. In: JORNADA INTERNACIONAL DE POLÍTICAS PÚBLICAS, São Luís, Anais... São Luís: Universidade Federal do Maranhão, 2009. Disponível em: <http://www. joinpp.ufma.br/jornadas/joinppIV/OLD/eixos_OLD/2.\%20 Transforma\%C3\%A7\%C3\%B5es\%20no\%2omundo\%20do\%20Trabalho/ QUEST\%C3\%83O\%20SOCIAL,\%20POL\%C3\%8DTICAS\%20SOCIAIS\%20 E\%20SERVI\%C3\%87O\%20SOCIAL\%20NO\%20CAPITA.pdf> Acesso em: 8 set. 2017. 
BRASIL. Ministério do Desenvolvimento Social e Combate à Fome. Relatórios Mensais de Atendimento CRAS e CREAS 2016, 2017. Brasília (DF), 2017a. Disponível em: <http://aplicacoes.mds.gov.br/ snas/vigilancia/index2.p>. Acesso em: 20 out. 2017.

BRASIL. Ministério do Desenvolvimento Social e Combate à Fome. Censo SUAS 2016. Brasília (DF), 2017b.

BRASIL. Ministério de Desenvolvimento Social e Combate a Fome. Resolução $\mathbf{n}^{\circ}$ 109, de 11 de novembro de 2009. Tipificação Nacional de Serviços Socioassistenciais. Disponível em: <http://www.mds. gov.br/assistenciasocial/arquivo/Tipificacao\%20Nacional\%20de\%20 Servicos\%20Socioassistenciais.pdf/view>. Acesso em: 8 set. 2017.

BRASIL. Ministério de Desenvolvimento Social e Combate à Fome. Centro de Referência Especializado de Assistência Social (CREAS). Guia de orientação. n. 1, 1. ver. Brasília (DF), 2007.

BRASIL. Ministério de Desenvolvimento Social e Combate à Fome. Política Nacional de Assistência Social. Brasília (DF), 2004.

BRASIL. Estatuto da Criança e do Adolescente. São Paulo: Cortez, 1990.

BRASIL. Constituição Federal Brasileira. Brasília (DF): Senado Federal, 1988.

ENGELS, Friedrich; KAUTSKY, Karl. O socialismo Jurídico. 2. ed. rev. São Paulo: Boitempo, 2012.

FRANÇA, Rosilene Marques Sobrinho de; FERREIRA, Maria D’Alva Macedo. A ação do Estado na Proteção Social a famílias de Crianças e Adolescentes frente às Contradições do Sistema Capitalista. In: TEIXEIRA, Solange Maria (Org.). Política de assistência social e temas correlatos. Campinas: Papel Social, 2016.

GOMES. Claúdia Maria. A tendência do debate sobre os direitos na cultura política contemporânea. Ser Social, Brasília (DF), n. 20, p. 9-3, jan./jun. 2007.

INSTITUTO BRASILEIRO DE GEOGRAFIA E ESTATÍSTICA. Síntese de indicadores sociais: uma análise das condições de vida da população brasileira. Rio de janeiro, 2014. (Estudos e Pesquisas 
Informação Demográfica e Socioeconômica, n. 34) Disponível em: <https://biblioteca.ibge.gov.br/visualizacao/livros/liv98965.pdf>. Acesso em: 10 set. 2017.

INSTITUTO BRASILEIRO DE GEOGRAFIA E ESTATÍ́STICA. Censo Demográfico 2010. Brasília (DF), 2010.

JACCOUD, Luciana; SILVA, Frederico Barbosa da.; BEGHIN, Nathalie. Políticas Sociais no Brasil: participação social, conselhos e parcerias. In: JACCOUD, L. (Org.). Questão social e políticas sociais no Brasil contemporâneo. Brasília (DF): IPEA, 2009.

LESSA, Sérgio. Para compreender Lukács. 4. ed. São Paulo: Instituto Lukács, 2015.

LUKÁCS, György. Para uma Ontologia do ser social. São Paulo: Boitempo, 2013.

MARCILIO, Maria Luiza. A roda dos expostos e a criança abandonada na História do Brasil. 1726-1950. In: FREITAS, Marcos Cezar de. (Org.) História Social da Infância do Brasil. $4^{a}$ ed. São Paulo. Cortez, 2001.

MONTAÑO, Carlos. Pobreza, "questão social” e seu enfrentamento. Serviço social e Sociedade, v. 110, p. 270-287, 2012.

MONTAÑO, Carlos; DURIGUETTO, Maria. Lúcia. Estado, Classe e Movimento Social. 3. ed. São Paulo: Cortez, 2011. (Biblioteca básica de Serviço Social, vol. 5).

ORGANIZAÇÃO DAS NAÇÕES UNIDAS. Declaração universal dos direitos Humanos. Rio de Janeiro: UNIC, ago. 2009. Disponível em: <http://www.onu.org.br/img/2014/og/DUDH.pdf>. Acesso em: 21 out. 2017.

PADILHA. Mirian Damasceno. Criança não pode trabalhar: a análise sobre o programa de erradicação do trabalho infantil e repercussão na sociabilidade familiar. Recife: CEPE, 2006.

RIZZINI, Irene. $\mathbf{O}$ século perdido: raízes históricas das políticas públicas para a infância no Brasil. 3. ed. São Paulo: Cortez, 2011. ROCHA, Sonia. Pobreza no Brasil: afinal, de que se trata?. Rio de Janeiro: FGV, 2003. 
SILVA, Ivone Maria Ferreira da. Questão Social e Serviço Social no Brasil: fundamentos sócio-históricos. 2. ed. Campinas: Papel Social; Cuiabá: EdUFMT, 2014.

SILVA, Maia Liduina de Oliveira. O Estatuto da Criança e do Adolescente e o Código de Menores: descontinuidades e continuidades. Serviço Social e Sociedade, São Paulo, n. 83, Ed. Especial, Criança e Adolescente, 2005.

SILVA, Maria Ozanira Silva e; YAZBEK, Maria Carmelita; GIOVANI, Geraldo Di. A política social brasileira no século XXI: a prevalência dos programas de transferência de renda. São Paulo: Cortez, 2004.

SPOSATI, Aldaíza et al. Assistência na trajetória das políticas sociais brasileiras. São Paulo: Cortez, 2009. 